\title{
Implications of lipid droplets in lung cancer: Associations with drug resistance (Review)
}

\author{
CHUNLAI JIN and PENG YUAN \\ Department of Surgery, First People's Hospital of Jinan, Jinan, Shandong 250011, P.R. China
}

Received December 3, 2019; Accepted May 27, 2020

DOI: 10.3892/ol.2020.11769

\begin{abstract}
Cancer cells usually show different metabolic patterns compared with healthy cells due to the reprogramming of metabolic processes. The process of lipid metabolism undergoes notable changes, leading to the accumulation of lipid droplets in cells. Additionally, this phenotype is considered an important marker of cancer cells. Lipid droplets are a highly dynamic type of organelle in the cell, which is composed of a neutral lipid core, a monolayer phospholipid membrane and lipid droplet-related proteins. Lipid droplets are involved in several biological processes, including cell proliferation, apoptosis, lipid metabolism, stress, immunity, signal transduction and protein trafficking. Epidermal growth factor receptor (EGFR)-activating mutations are currently the most effective therapeutic targets for non-small cell lung cancer. Several EGFR tyrosine kinase inhibitors (EGFR-TKIs) that target these mutations, including gefitinib, erlotinib, afatinib and osimertinib, have been widely used clinically. However, the development of acquired resistance has a major impact on the efficacy of these drugs. A number of previous studies have reported that the expression of lipid droplets in the tumor tissues of patients with lung cancer are elevated, whereas the association between elevated numbers of lipid droplets and drug resistance has received little attention. The present
\end{abstract}

Correspondence to: Dr Peng Yuan, Department of Surgery, First People's Hospital of Jinan, 132 da Ming Lake Street, Jinan, Shandong 250011, P.R. China

E-mail: pengyuan_dr@126.com

Abbreviations: EGFR, epidermal growth factor receptor; NSCLC, non-small cell lung cancer; TKI, tyrosine kinase inhibitor; TG, triglyceride; ER, endoplasmic reticulum; SCD1, stearoyl-CoA desaturase; GPAT, glycerol-3-phosphate acyltransferase; DGAT, diacylglycerol-o-acyltransferase; $\quad \mathrm{PC}, \quad$ phosphatidylcholines; HSL, lipase E, hormone-sensitive type; DAG, diglyceride; MAG, monoglyceride; FASN, fatty acid synthase; SREBP, sterol regulatory element binding protein; ROS, reactive oxygen species; g-PPT, (20S)-protopanaxatriol

Key words: lung cancer, non-small cell lung cancer, drug resistance, epidermal growth factor receptor, tyrosine kinase inhibitors, lipid droplet review describes the potential association between lipid droplets and drug resistance. Furthermore, the mechanisms and implications of lipid droplet accumulation in cancer cells are analyzed, as wells as the mechanism by which lipid droplets suppress endoplasmic reticulum stress and apoptosis, which are essential for the development and treatment of lung cancer.

\section{Contents}

1. Introduction

2. The lipid droplet composition and generation process

3. Degradation of lipid droplets

4. Lipid droplet accumulation in lung cancer cells

5. The implications of lipid droplet in cancer cells

6. Associations between lipid droplets and drug resistance

7. Effects of lipid droplets on cellular stress and apoptosis

8. Potential mechanism of lipid droplets regulating EGFR activation

9. Conclusions

\section{Introduction}

Lipid droplets are organelles with a unique structure composed of a neutral lipid core and a monolayer phospholipid membrane embedded with several lipid droplet-associated proteins. For hundreds of years, lipid droplets were thought to be the only particles passively storing or released energy in the cell. However, in the last 20 years, lipid droplets have been extensively investigated, and lipid droplet biology is becoming one of the most popular and cutting-edge areas in the field of organelle study (1-3). Several studies have shown that lipid droplets are a complex, active and dynamic type of multi-functional organelle that moves along the cytoskeleton within the cell and interacts with other organelles, including the endoplasmic reticulum, mitochondria, nucleus, peroxisomes, autophagosomes and Golgi, to regulate the metabolism and energy balance of cells (4-6). In addition, studies have found that lipid droplets also have an important role in cell proliferation, apoptosis, metabolism, stress, immunity, membrane transport, protein degradation, signal transduction and transcriptional regulation (1,5,7-10). Therefore, lipid droplets have a lot of physiological functions beyond lipid storage (1). For example, a recent study reported that lipid 
droplets contribute to the airway inflammation by driving pathogenic group 2 innate lymphoid cells (11). Moreover, lipid droplets can decrease the expression of oxidized phospholipids, such as 4-hydroxynonenal (HNE) in glia cells, which can protect against oxidative stress in brain (12). Furthermore, lipid droplets can provide energy rapidly in brown adipocytes by interacting with mitochondria under cold stress (13). If the lipid droplets are not present due to gene editing or inhibition of long-chain fatty acid synthesis, the cell becomes lipotoxic, which can induce severe cellular stress and even cell apoptosis (14). A typical feature of cancer cells is that their metabolism is different from healthy cells. Usually, energy metabolism, particularly lipid metabolism, in cancer cells undergoes reprogramming (15-17). Healthy cells absorb free fatty acid directly for energy production, and the lipid synthesis is at a low level, but lipid synthesis is activated and numerous fatty acids and lipids are formed in tumor cells (15-17). The lipid synthesis pathway in cancer cells is usually constitutively activated, and the lipid breakdown process is inhibited $(18,19)$. These excess lipids are often stored in lipid droplets, resulting in a significantly higher content of lipid droplets in cancer cells and cancerous tissues compared with healthy cells and tissues. Therefore, lipid droplet accumulation is often considered a prominent feature of cancer cells $(20,21)$. Such intracellular lipid droplet accumulation often leads to cellular abnormalities, including cellular insulin resistance, oxidative stress and dysregulated transcription (22-27).

Lung cancer is one of the most common cancer types in the world, with $\sim 85 \%$ of lung cancer cases being non-small cell lung cancer (NSCLC) in 2018 (28). It was initially expected that the use of molecularly targeted anticancer drugs (such as tyrosine kinase inhibitors) could inhibit tumor growth; however, numerous patients develop resistant tumors after 1-2 years of treatment $(29,30)$. The discovery of activating mutations in the epidermal growth factor receptor (EGFR) in 2004 provided a new avenue the treatment of lung cancer $(31,32)$, through which individualized treatment options can be developed by targeting specific genetic mutation sites. There are activating mutations located in the tyrosine kinase domain of the EGFR gene, including a 19-exon deletion and a point mutation in the 21 exon L858R (31-33). These activating mutations make EGFR highly sensitive to EGFR-TKIs molecular targeted drugs, such as gefitinib and erlotinib, but patients also develop resistance to these drugs (34-36). Previous studies have shown that changes in lipid metabolism in cancer cells are associated with EGFR-TKI resistance (37-39), and the inhibition of intracellular lipid droplet synthesis can reverse the resistance of cancer cells to gefitinib (40). This result suggests that lipid droplet accumulation in cancer cells may be one of the causes of EGFR-TKI resistance. The combined use of lipid droplet-targeting drugs with TKIs in patients with EGFR-TKI resistance may have an improved therapeutic effect compared with TKI treatment alone. The present review explains the association between lipid droplet accumulation and drug resistance in lung cancer from the perspective of lipid droplet biology.

\section{The lipid droplet composition and generation process}

A lipid droplet is a spherical organelle whose core contains a wide variety of neutral lipids, including cholesteryl esters, retinyl esters and triglycerides with saturated or unsaturated chains $(2,3,41,42)$ (Fig. 1A). The neutral lipid core is coated by a single layered phospholipid membrane, and its phospholipid components are diverse, including phosphatidylcholine (PC), phosphatidylethanolamines, phosphatidylglycerol, phosphatidylinositol and phosphatidylserine (43) (Fig. 1A). Lipid droplet surfaces are characterized by phospholipid packing defects, which makes the lipid droplet expose a rougher interface toward the aqueous cytosol. The phospholipid packing defects means that neutral lipids are exposed in some areas on the lipid droplets surface. Therefore, proteins containing large hydrophobic helical domains can be recruited to the packing defects of surface (44) (Fig. 1A). Different types of cells, and even different cells of the same type, have different lipid droplet sizes, content, lipid components and associated protein types under different metabolic states (2,3). Following advances in mass spectrometry, the proteomes of lipid droplet-associated proteins, as well as the lipid components of individual droplets, have been resolved. Among them, TG and PC are the most commonly dominant components of lipid droplets. For example, although the components of the fatty acid chains of TG and PC are diverse, the 16:0/18:1/18:1 (fatty acid chains) of TG and the 18:1/16:0 of PC are dominant in HepG2 cells (45).

Electron microscope and fluorescent images of intracellular lipid droplets have revealed that lipid droplets are most often in contact with the endoplasmic reticulum (ER) and mitochondria $(5,8,9)$. It is currently accepted that intracellular lipid droplets are produced in the ER $(2,3)$ (Fig. 1B). The ER surface contains various lipid synthase enzymes, including acyl-CoA synthetase long chain family member 3, stearoyl-CoA desaturase (SCD1), glycerol-3-phosphate acyltransferases (GPATs), acylglycerol-3-phosphate-o-acyltransferases, phosphatidate phosphatases and diacylglycerol-o-acyltransferases (DGATs) $(2,3)$. TG is produced by the catalysis of these enzymes and is stored in the middle of the bilayer membrane of the ER in a len structure. Like TG accumulation, lipid droplets separate from the ER into the cytoplasm in a budding manner $(2,3)$. These newly formed lipid droplets can interact with the ER and complete the transport of lipids from the ER to the lipid droplets through a bridge structure $(8,9)$. In addition, TG synthases, such as GPAT4 and DGAT2, can be transferred to the surface of lipid droplets from the ER via direct contact, therefore TGs can be synthesized on the surface of the lipid droplets and then transferred to its lipid core $(46,47)$. It should be noted that lipid droplets are different from vesicles, which are a bilayer-phospholipid-membrane organelle derived from ER, in terms of structure. For example, vesicles consist of a phospholipid bilayer with an aqueous core, whereas lipid droplets consist of phospholipid monolayer and neutral lipid core (46). Several previous studies have reported that the surface proteins of lipid droplets can transfer during lipid droplets contact with other organelles $(5,9,10,46)$. Therefore, both vesicles and lipid droplets are involved in transportation of proteins. Newly synthesized TG can be stored in lipid droplets or released into the blood as very low-density lipoproteins in the liver and transferred to other tissue cells $(48,49)$. A previous study has shown that the nuclear inner membrane also has lipid synthesis activity and is the site where phosphatidic acid and DAG accumulate (50) (Fig. 1B). DGAT2 on the inner nuclear membrane converts DAG into TG and 


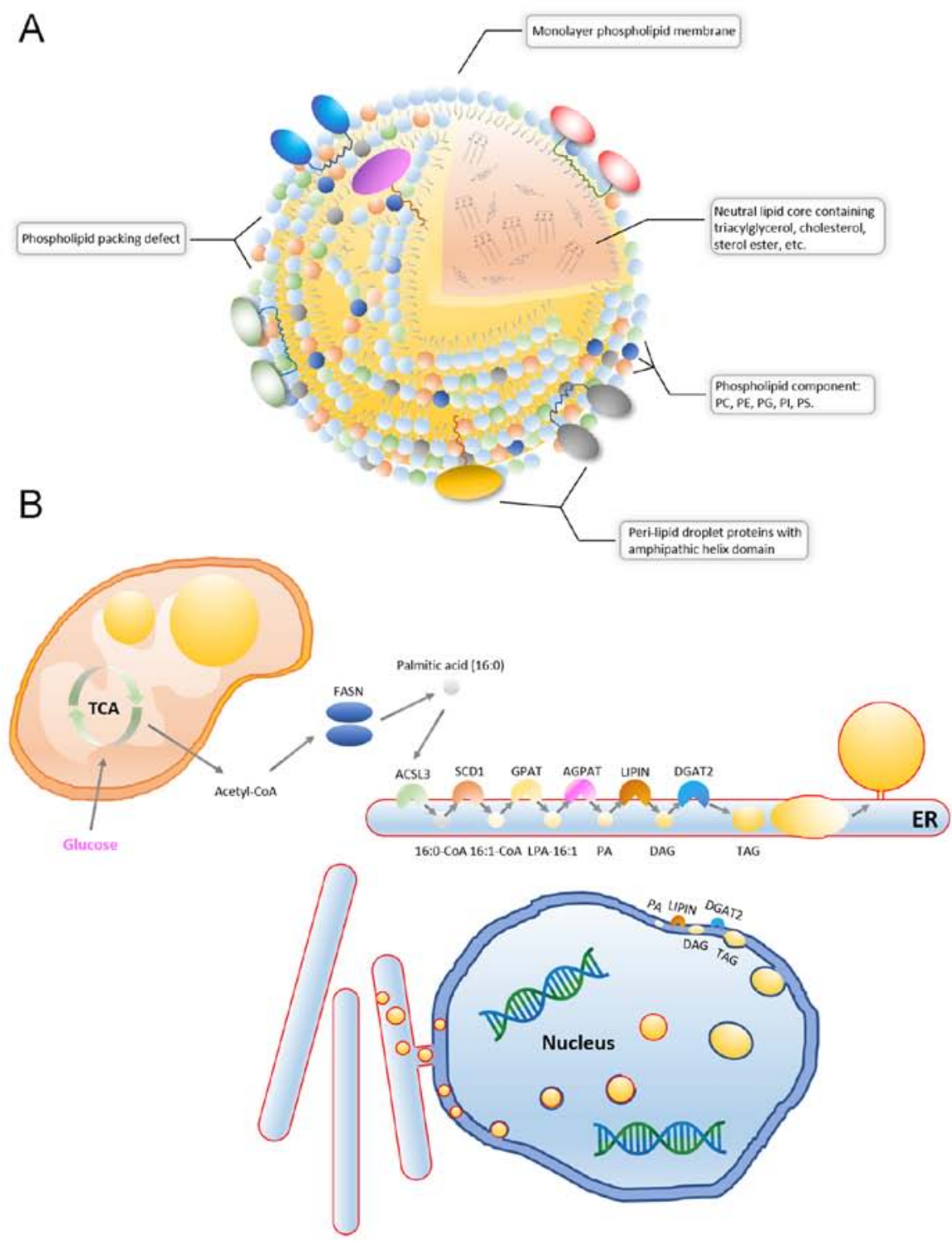

C

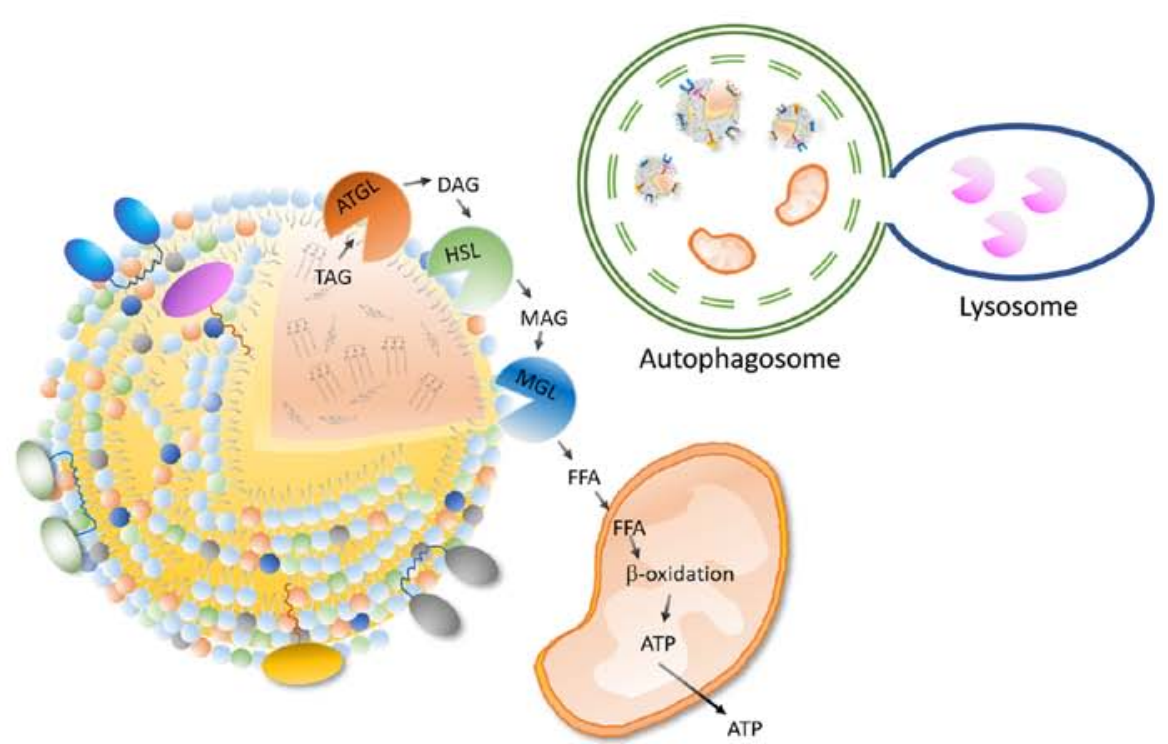

Figure 1. Composition, synthesis and degradation of lipid droplets. (A) A lipid droplet is a spherical organelle with a core containing a wide variety of neutral lipids. Lipid droplet surfaces are characterized by phospholipid packing defects, and numerous proteins containing large hydrophobic helical domains can be recruited to the packing defects of the surface. (B) The ER, inner nuclear membrane and mitochondria can generate lipid droplets. (C) There are two main processes of lipid droplet breakdown: Degradation by glyceride hydrolases, such as patatin-like phospholipase domain containing 2 and HSL, and lipase hydrolysis by lysosomes during lipophagy. ER, endoplasmic reticulum; HSL, lipase E, hormone-sensitive type; 
stores TG in the middle of the nuclear membrane bilayer of phospholipids, which is then released into the nucleoplasm by budding (50). In addition, the lipid droplets in the lumen of the ER can be transferred to the nuclear membrane. The lipid droplets coated with the inner nuclear membrane are then released into the nucleus, the coated nuclear membrane breaks and then the encapsulated lipid droplets are released (51). Recent findings suggest that lipid droplets are also produced inside the mitochondria (52) (Fig. 1B). After knocking out tissue-specific sorting nexin Snx31 in urothelial umbrella cells, multivesicular bodies (MVBs) were no longer observed and lipid droplets were produced inside the mitochondria, which were further degraded by autophagy (52). This result suggests that mitochondria also have lipogenic activity. Therefore, the endoplasmic reticulum, nucleus and mitochondria are able to synthesize lipid droplets.

\section{Degradation of lipid droplets}

Lipid droplets are the site of lipid storage and breakdown (Fig. 1C). There are two main processes of lipid droplet breakdown, including degradation by glyceride hydrolases, such as ATGL and lipase E, hormone-sensitive type (HSL), and lipase hydrolysis mediated by lysosomes during lipophagy (53) (Fig. 1C). In degradation by glyceride hydrolases, ATGL binds to the surface of the lipid droplets and, upon activation, begins to hydrolyze TG into DAG (53). HSL is then recruited to the surface of the lipid droplets to hydrolyze the DAG to monoglyceride (MAG) (53-55). MAG is eventually converted to free fatty acids by MAG lipase and released into the cytosol (56). The roles of free fatty acids in the cytoplasm are diverse, including functions in mitochondrial $\beta$-oxidation for energy supply, as a substrate for lipid and phospholipid membrane synthesis and as a ligand signaling molecule binding to transcriptional factors (57-59). In lipase hydrolysis, lipid droplets can be recognized and encapsulated by autophagic vacuoles, forming autophagosomes that fuse with lysosomes to yield fatty acid and energy. There is also a lysosomal lipase that can degrade neutral lipids, during which the lipid droplet surface proteins are simultaneously degraded to complete the recycling process of the lipid molecule (60).

\section{Lipid droplet accumulation in lung cancer cells}

In 1963, Aboumrad et al (61) found a large number of lipid vesicles in the cytoplasm of breast tumor cells. In 1973, Ramos and Taylor (62) found, in clinical studies, that lipid-containing breast tumors were associated with higher tumor grades (62). Current research shows that tumor cells not only differ from healthy cells in their sugar metabolism (the Warburg effect) (63), but also undergo marked changes in their lipid metabolism. Among these changes, the fatty acid synthase (FASN) and sterol regulatory element binding protein (SREBP) families of proteins have important roles (64-70). Non-cancer cells can regulate intracellular lipid levels by regulating lipid uptake, synthesis and decomposition, while cancer cells are able to take up more lipids and enhance lipid synthesis $(71,72)$. In addition, non-cancer cells preferentially take up exogenous fatty acids to maintain FASN expression at a low levels, whereas the levels of FASN expression in cancer cells are high and are overactivated, which increases lipid synthesis and leads to an accumulation of lipid droplets $(73,74)$ (Fig. 2). Previous studies have shown that adipophilin (a lipid-associated protein) expression is higher in lung adenocarcinoma compared with normal lung tissues $(75,76)$. In addition, adipophilin expression is associated with a poor prognosis for patients with lung adenocarcinoma $(75,76)$. Another study has also shown that cell lines containing resistant EGFR mutations (including HCC827GR and H1975) have higher lipid droplet content compared with cell lines containing EGFR mutations sensitive to TKI treatment (40). In addition, drug-resistant cell lines show greater lipid droplet level after TKI treatment (40). Database analysis indicated that lipid metabolism-associated gene expression levels are higher in PC9GR (drug-resistant) cells compared with PC9 (drug-sensitive) cells (40) (Fig. 2). This evidence suggests a potential association between abnormal lipid metabolism and drug resistance.

\section{The implications of lipid droplet in cancer cells}

The role of lipid droplets in cancer is a novel field of research; however, there is evidence suggesting that increased lipid droplet content is associated with tumor aggressiveness and chemotherapy resistance (77-81). Numerous tumorigenic proteins, including PI3K, ERK1, ERK2 and caveolins, were found to be recruited in lipid droplets $(80,82-84)$. In addition, lipid droplets are associated with maturation of immature dendritic cells and the activation of $\mathrm{T}$ cells, suggesting that lipid droplets are also associated with tumor development and progression $(85,86)$. It is well known that lipid droplets are important sites for intracellular lipid metabolism and are closely associated with the production of various lipids and their derivatives $(80,87)$. Some lipid metabolites, such as arachidonic acid [an important substrate for prostaglandin (PGE)2 synthesis] and eicosanoids, are important for the immune process as PGE2 can inhibit the proliferation of T cells $(86,87)$. For example, Accioly et al (79) reported that lipid droplets in colon adenocarcinoma cell lines and colon cancer biopsy tissues were significantly higher compared with these those in normal cells and paired normal tissues. In addition, high lipid droplet content is associated with high PGE2 synthesis (88). It was found that cyclooxygenase (COX)-2 (a key enzyme in PGE2 synthesis) is recruited in lipid droplets, which led PGE2 synthesis in lipid droplets (78) (Fig. 3A). PGE2 is the most highly expressed PGE and is abundant in tissues containing a number glands, such as the colon, lung, breast and brain tissue (89-92). PGE2 plays an important role in promoting tumor growth (93), as it can promote tumor cell proliferation and migration (92).

As a site of lipid storage, lipid droplets can provide the necessary lipid components for cell proliferation, such as cell membrane components like phospholipids, through lipophagy (94-96) (Fig. 3B). In the process of cancer cell proliferation, lipid droplets provide both cell membrane components and a large amount of energy, thereby maintaining cancer cell proliferation and survival (78,97-100) (Fig. 3B). For example, in the process of colon cancer cell proliferation, where the cell energy demand is large, the rich lipid droplet content in these cell is compatible with this demand (100). Notably, Penrose et al (100) also observed an association 


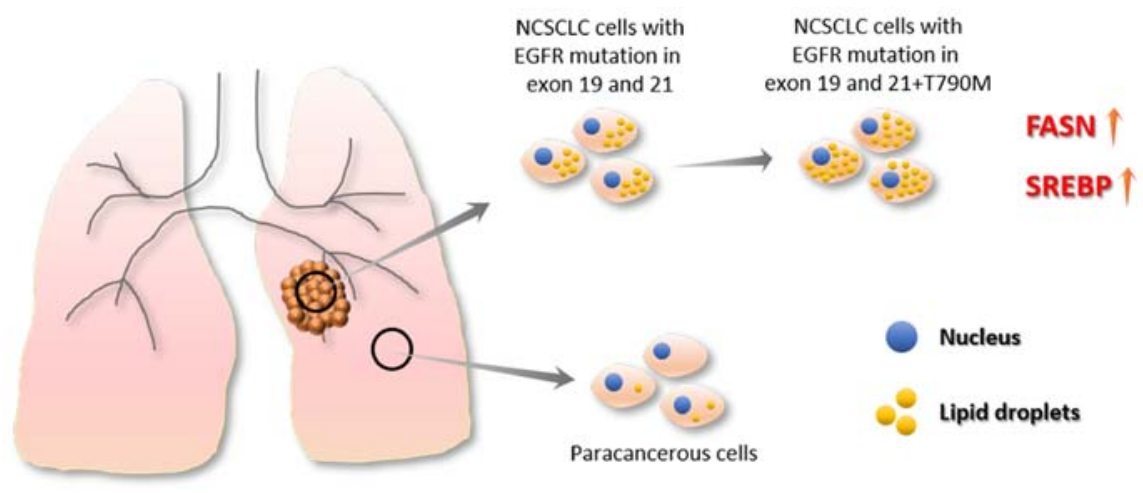

Figure 2. Lipid droplet accumulation in lung cancer cells. Tumor cells not only differ from healthy cells in their sugar metabolism but also undergo changes in lipid metabolism. Among them, the FASN and the SREBP families of proteins serve an important role. NSCLC cells with EGFR mutations in exon 19 and 21 showed higher lipid droplet content compared with para-cancerous cells. Moreover, cell lines containing resistant EGFR mutations (HCC827GR and H1975) have higher lipid droplet content compared with cell lines containing sensitive EGFR-activating mutations. FASN, fatty acid synthase; SREBP, sterol regulatory element binding protein; NSCLC, non-small cell lung cancer; EGFR, epidermal growth factor receptor.
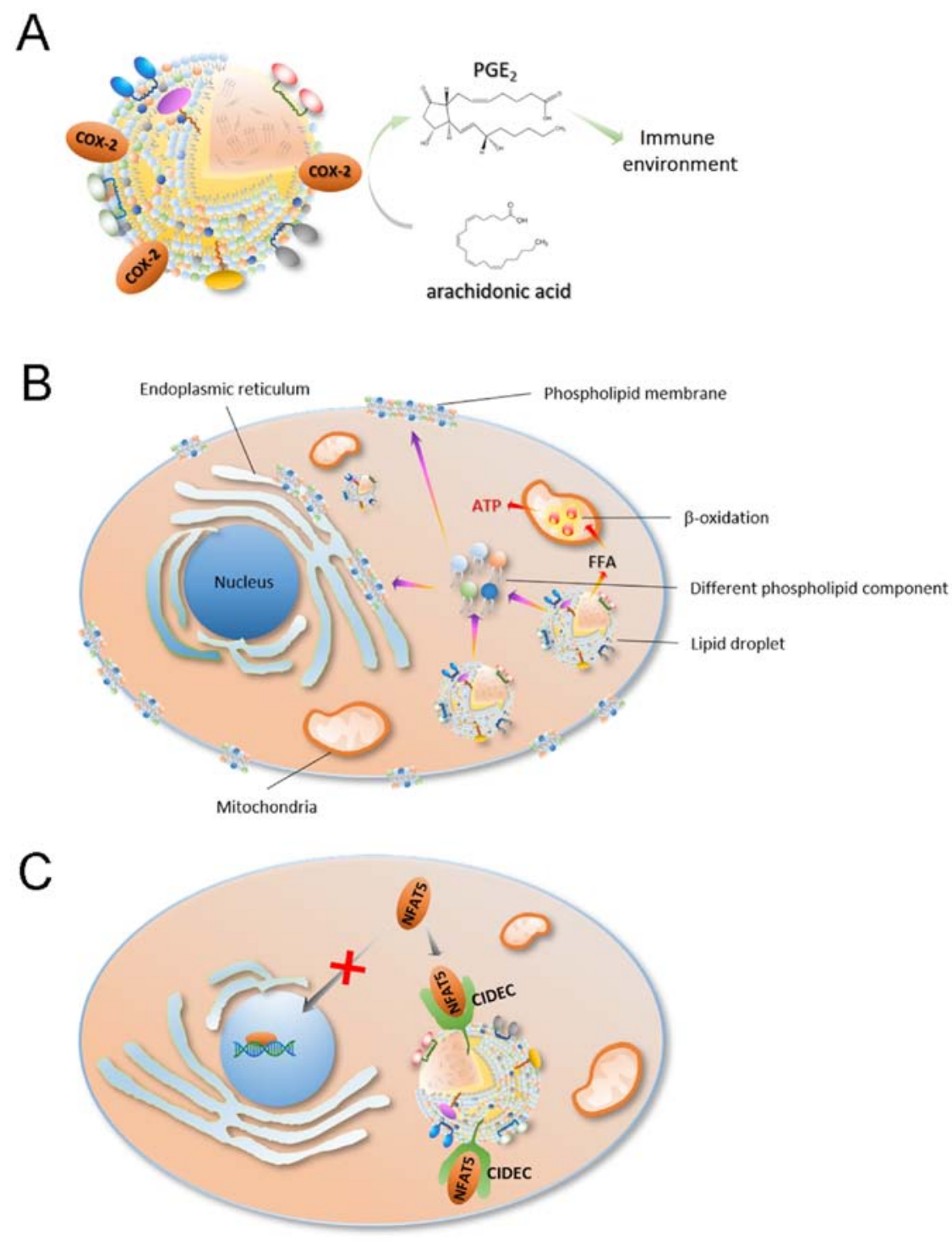

Figure 3. The implications of lipid droplets in cancer cells. (A) COX-2 (a key enzyme in PGE2 synthesis) is recruited in lipid droplets, which allows lipid droplets to synthesize PGE2. (B) Lipid droplets can provide the necessary lipid components for cell proliferation, such as cell membrane components like phospholipids, through lipophagy. In the process of cancer cell proliferation, lipid droplets provide cell membrane components and a large amount of energy, thereby maintaining cancer cell proliferation and survival. (C) Lipid droplets can also regulate the proliferation of cancer cells by transcriptional regulation. CIDEC recruited to the surface of lipid droplets contains a protein domain that binds to NFAT5, which can arrest NFAT5 on the surface of lipid droplets and prevent its transcriptional function in the nucleus. COX, cyclooxygenase; PGE, prostaglandin E2; CIDEC, cell death inducing DFFA like effector C; NFAT, nuclear factor of activated $\mathrm{T}$ cells 5 ; FFA, free fatty acid. 
between increased lipid droplets and EGFR signaling in colon cancer (100). Colon cancer cell proliferation is regulated by EGFR signaling, stimulating an increase in LD density in an EGFR expression and activation-dependent manner, and increasing individual cellular capacity for lipid synthesis (100). This effect is enhanced by the EGFR-induced PI3K/mTOR pathway and PGE2 synthesis and negatively regulated by forkhead box protein O1/ NAD-dependent protein deacetylase sirtuin-6-mediated tumor suppressor inactivation (100).

Lipid droplets can also regulate the proliferation of cancer cells by transcriptional regulation (Fig. 3C). Nuclear factor of activated T-cells (NFAT) 5 is a member of the NFAT protein family and has a DNA binding domain similar to the Rel-homology region of NF- $\kappa \mathrm{B}$ (101). NFAT5 has an important role in embryonic development, cell proliferation, immune response and the cellular stress response (101). In addition, NFAT5 plays an important role in the development, invasion and proliferation of tumor cells (102). For example, NFAT5 can promote the proliferation and invasion of renal cancer cells, and promote the infiltration of melanoma (103-107), which suggests that NFAT5 may also be able to promote tumor cell proliferation and infiltration in other types of cancer. Furthermore, Meng et al (108) found that NFAT5 regulates lung cancer cell proliferation, migration and infiltration (108). Previous studies have found that cell-death inducing DFF45-like effector c (CIDEC) recruited to the surface of lipid droplets contains a protein domain that binds to NFAT5, which can bind to NFAT5 on the surface of lipid droplets and prevent its transcriptional function in the nucleus (22).

The high lipid droplet content in cancer cells may enhance migration. Tomin et al (109) knocked out triglyceride lipase (ATGL) in the lung cancer A549 cells and demonstrated that a large number of lipid droplets was accumulated in the cells. In addition, cellular phospholipids and bioactive lipids (such as lyso- and ether-phospholipids) are also upregulated. Proteomic data showed that pro-oncogene SRC kinase expression is upregulated, and phosphorylated (p-)SRC (Y416 p-SRC, activated SRC) expression is also increased (109). Lung cancer cells exhibit faster migration rates, suggesting greater tumor aggressiveness (108).

In summary, cancer cells undergo hyperactivation of de novo lipid synthesis due to the rearrangement of lipid metabolism, which causes cellular lipid droplets to accumulate. A high content of lipid droplets could provide energy and various lipid components for cancer cell proliferation and could regulate cancer cell proliferation, migration and infiltration by affecting biological processes, such as transcriptional regulation.

\section{Associations between lipid droplets and drug resistance}

There are a limited number of reports investigating the association between of drug resistance and lipid droplets in cancer cells. A recent study by Huang et al (40) revealed an association between lipid metabolism rearrangement and EGFR-TKI resistance in NSCLC cancer cells (40) (Fig. 4). The authors found that NSCLC tumor tissue had higher lipid droplet content compared with para-cancerous tissue, and TKI treatments could further increase lipid droplet content in tumor tissue. In addition, the gefitinib-resistant cell lines,
HCC827GR (T790M), H1975 and PC9GR, expressed more lipid droplets compared with EGFR-TKI-sensitive cell lines, HCC 827 and PC-9, which suggests an association between lipid droplet content and drug resistance (40). In addition, after treatment with oleic acid, even EGFR-TKI-sensitive cell lines showed decreased sensitivity to EGFR-TKI and upregulated p-EGFR. This result indicates that oleic acid treatment abolished the inhibitory effect of gefitinib on the activation of the p-EGFR/p-AKT/p-ERK signaling pathway (40). When injecting combined gefitinib and oleic acid treated cells into a HCC827 mice to establish a xenograft tumor model, oleic acid attenuated gefitinib-induced apoptosis and reduced the cytotoxicity of gefitinib. Then, the authors treated the cells with (20S)-protopanaxatriol (g-PPT) (targeting SCD1, inhibiting lipid synthesis) to effectively reduce the number of intracellular lipid droplets (40). Notably, the authors found that EGFR-TKI-resistant mutant cell lines (HCC827GR and H1975) had increased sensitivity to EGFR-TKI after the number of cellular lipid droplets decreased (40). Moreover, the combined use of gefitinib and g-PPT could inhibit cancer cell proliferation and downregulate p-EGFR expression levels (40). In addition, the combined use of gefitinib and g-PPT inhibited the activation of the p-EGFR/p-AKT/p-ERK signaling pathway and promoted apoptosis in vitro and in vivo. These results indicate that the inhibition of lipid droplet formation can reverse gefitinib resistance caused by EGFR-TKI resistant mutations and enhance the cytotoxicity of gefitinib, thereby promoting gefitinib-induced apoptosis (40). In addition, some evidence has shown that mutations in EGFR may be derived from changes in cellular metabolism (110-112). Therefore, changes in lipid metabolism may promote the complex development of NSCLC and promote drug resistance in cancer cells. Huang et al (40) provides a novel perspective for the treatment of drug-resistant NSCLC (40). Drug targeting lipid droplets can reduce drug resistance during the treatment of drug-resistant NSCLC to enhance the cytotoxicity of drugs on cancer cells (40).

Cotte et al (99) investigates chemotherapeutic drug resistance in colon cancer and illustrates the molecular mechanism of lipid droplet accumulation and drug resistance (5-fluorouracil) (99) (Fig. 4). The authors found that LD accumulation drives cell-death resistance to 5-fluorouracil and oxaliplatin treatments both in vitro and in vivo. The treatment of 5-fluorouracil and oxaliplatin can promote lipid droplet accumulation. Notably, the high fat droplet cell line HT29 and the low-fat cell line SW620 showed markedly different sensitivities to 5-fluorouracil and oxaliplatin. It was found that lysophosphatidylcholine acyltransferase (LPCAT)2-induced lipid droplet accumulation plays an important role in the resistance to chemotherapeutic drugs. Overexpression of LPCAT2 in SW620 cells can increase lipid droplet content and inhibit apoptosis induced by chemotherapeutic drugs. In terms of its mechanism, LPCAT2-induced lipid droplet accumulation maintains the ER homeostasis of cells, inhibits the activation of all caspases, and thereby inhibits extrinsic, intrinsic and ER stress-mediated apoptotic processes (99). Chemotherapy drugs can activate eukaryotic translation initiation factor (EIF)2a and C/EBP-homologous protein (CHOP), thereby leading to ER stress and further inducing apoptosis. LPCAT2-mediated lipid droplet accumulation can reduce EIF2a phosphorylation 

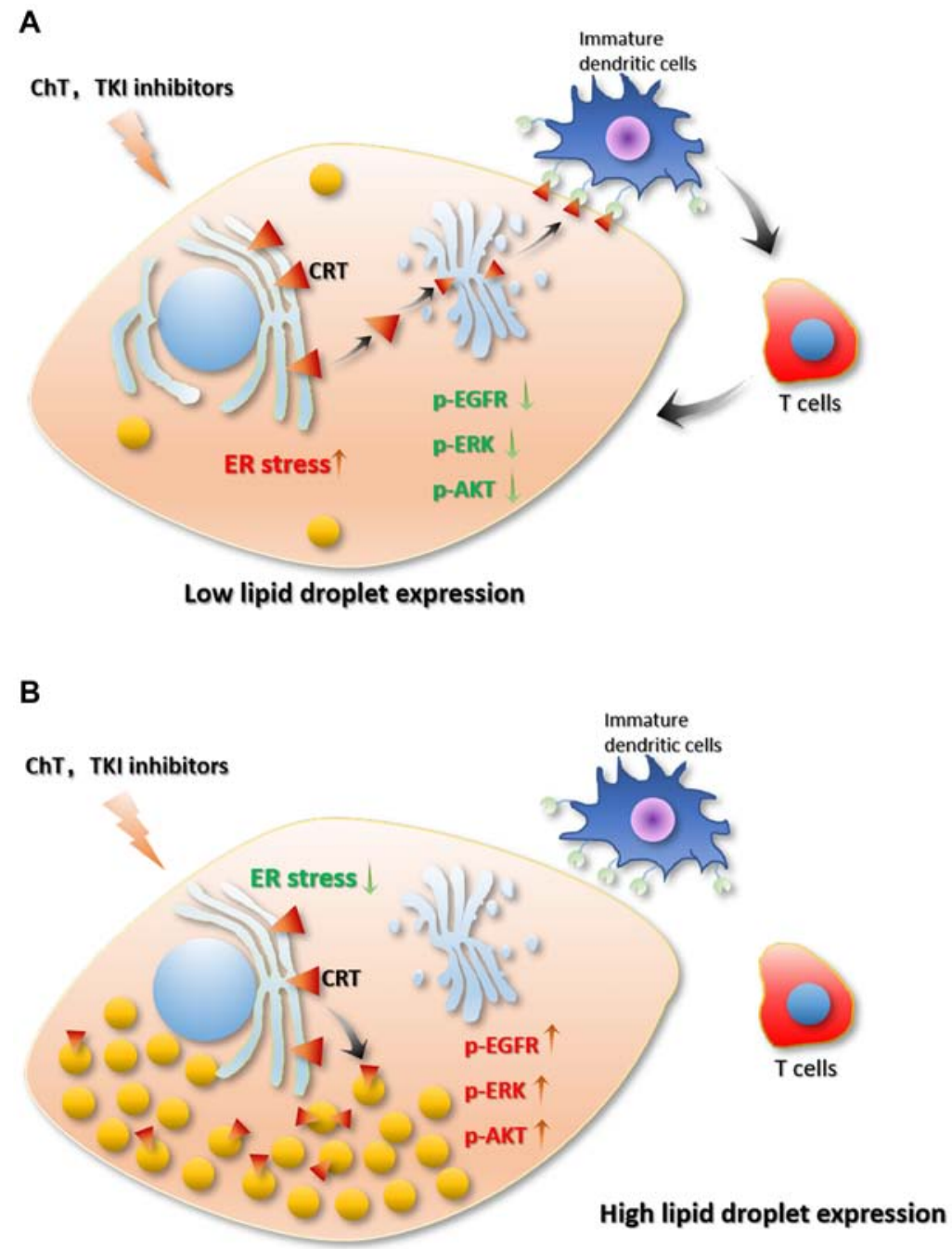

Figure 4. Association between lipid droplets and drug resistance. Tumor cells with (A) low lipid droplet content and those with (B) high lipid droplet content and the different sensitivities to ChT or TKIs treatment. p-EGFR/p-ERK/p-AKT pathways were inhibited in cells with low lipid droplet content after ChT or TKIs treatment. Then, ER-stress is activated, and CRT on the ER membrane is translocated to the Golgi and exposed to cell membrane. Therefore, immature dendritic cells can recognize CRT exposed on the cell membrane and activated T cells to induce tumor cell apoptosis. However, the p-EGFR/p-ERK/p-AKT pathways were not affected by ChT or TKI treatment. Lipid droplets can also enhance the capacity of cells against stress, as they suppress the exposure of CRT on the cell membrane. Additionally, further T cells cannot be activated. Therefore, higher lipid droplet content enhanced tumor survival. ChT, chemotherapy; TKI, tyrosine kinase inhibitor; p-, phosphorylation-; EFGR, epidermal growth factor receptor; ER, endoplasmic reticulum; CRT, calreticulins.

and decrease BiP (ER chaperone) protein levels and CHOP accumulation. SW620 and HT29 cells were then treated with triacsin $\mathrm{C}$ (a long-chain fatty acid synthase inhibitor) to reduce the increase in cellular lipid droplets induced by chemotherapeutic drug treatment. Triacsin $\mathrm{C}$ treatment can enhance the sensitivity of the high lipid droplet content cell line HT29 against chemotherapy drugs. In addition, lipid droplets can isolate calreticulins (CRTs) in cells and recruit CRTs to the lipid droplet surface to block CRT exposure, thereby reducing the immunogenicity of tumor cells, which could impair the therapeutic effects of chemotherapy drugs. CRT is important for the maturation of immature dendritic cells. The CD91 protein on the surface of immature dendritic cells can bind to CRT on the surface of tumor cells, and the mature dendritic cells can further activate the T cells (99).

In summary, the rearrangement of lipid metabolism in cancer cells induces lipid droplet accumulation, which could impair the therapeutic effect of drugs by inhibiting drug-induced apoptosis. Lipid droplets provide lipid substrates and energy for the proliferation of cancer cells; therefore, lipid droplet accumulation is disadvantageous for the treatment of cancer.

\section{Effects of lipid droplets on cellular stress and apoptosis}

Chemotherapy drugs, programmed death (PD)-ligand 1/PD-1, or TKI drugs for NSCLC treatment are all based on the principle of promoting cancer cell stress and apoptosis $(113,114)$. Previous studies have shown that lipid droplets are associated with cellular stress and apoptosis processes. Firstly, there is an association between lipid droplets and cell stress. When stress occurs, such as a lack of nutrients or elevated levels of reactive oxygen species (ROS), cells will produce a large number of lipid droplets. In addition, increased lipid droplet levels lead to resistance to cell stress and maintains cell homeostasis (14). During evolution, cells have established an energy-sensing system to accommodate for the uncertainty of the nutrient supply (115). AMP-activated protein kinase (AMPK) and 


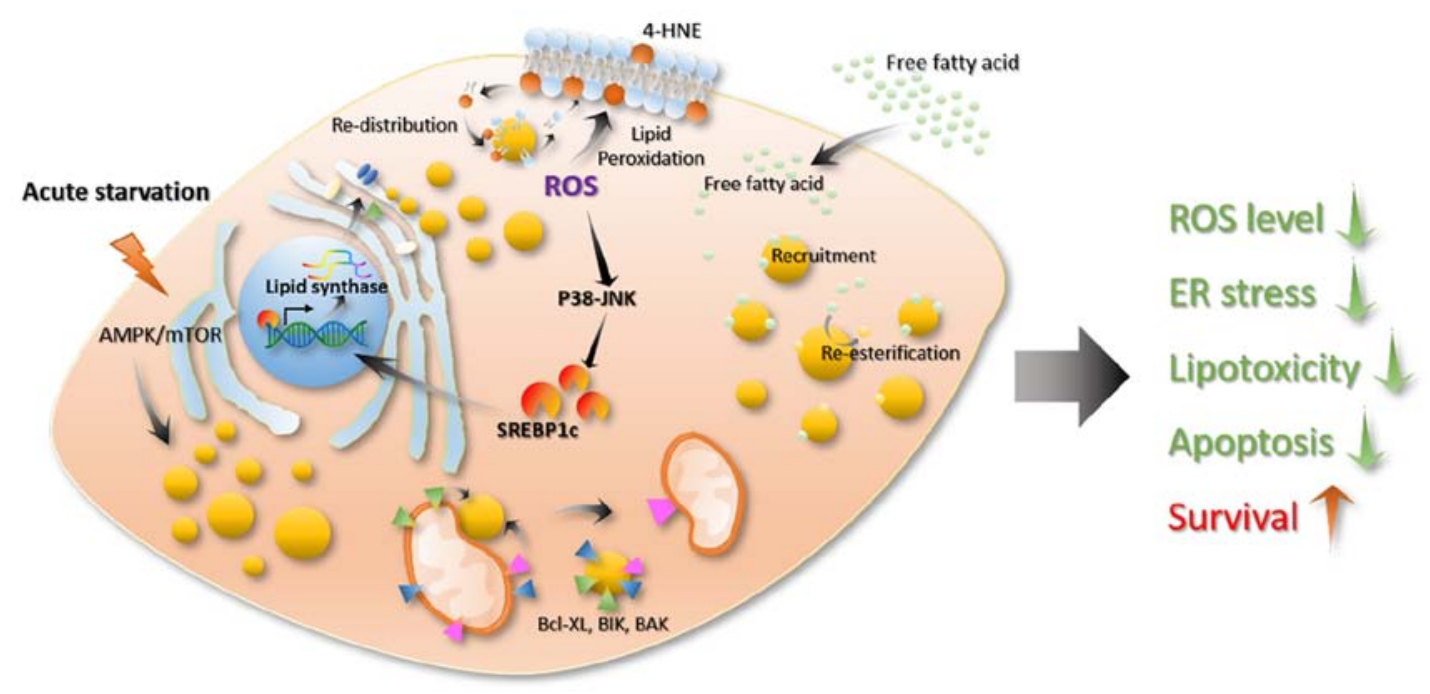

Figure 5. Effects of lipid droplets on cellular stress and apoptosis. When stress occurs, such as a lack of nutrients or elevated levels of ROS, cells will produce a large number of lipid droplets. In addition, increased lipid droplets will resist cell stress and maintain cell homeostasis. Acute nutritional restriction promotes lipid droplet formation. This process is associated with autophagy induced by mTORC1 inactivation. Excess lipids cause cellular lipotoxicity when cells take up large quantities of lipids exceeding their storage or depletion capacity. The production of lipid droplets reduces the cellular lipid toxicity caused by excess lipids and maintains cell homeostasis. ROS affects the formation and degradation of cellular lipids. ROS can oxidize phospholipid membranes to increase their content of 4-HNE (product of lipid oxidation, which causes protein damage) in cell membranes. Lipid droplets can re-distribute the oxidized lipids of the membrane, thereby reducing the oxidized lipid content on the cell membrane and lowering the levels of 4-HNE to promote cell survival. Lipid droplets can also resist cellular stress by interacting with other organelles. Lipid droplets can be in contact with the mitochondria and transfer apoptosis-associated proteins, such as BAX, BCL-2 and BCL-Xl, from the surface of the mitochondria to the surface of the droplet. This process can prevent mitochondrial damage and inhibit apoptosis. ROS, reactive oxygen species; 4-HNE, 4-hydroxynonenal; AMPK, AMP-activated protein kinase; SRECB1c, sterol regulatory element binding protein $1 \mathrm{c}$.

the mammalian target of rapamycin complex 1 (mTORC1) are highly conserved among different species and are central to cellular metabolic regulation (115-118). AMPK can be activated by nutrients, genotoxins, xenobiotics and oxidative stress (115). Activation of AMPK inhibits the synthesis of fatty acids, sterols and triglycerides $(116,119-121)$ and promotes glycolysis, mitochondrial activity and fatty acid oxidation (120). On the contrary, mROTC1 regulates the synthesis of fatty acids, sterols and glycolipids by regulating SREBP transcription factors (122-124). In mammalian cells, acute nutritional restrictions promote lipid droplet formation (98). This process is associated with the autophagy induced by mTORC1 inactivation (125). Through this process, cells can preserve several lipid precursors and energy to enable cells to survive in a state of energy deficiency (Fig. 5) (126-128). Excess lipids cause cellular lipo-toxicity when cells take up large quantities of lipids exceeding their storage or depletion capacities (129). Then, the lipid synthesis pathway is activated, transforming the free unesterified fatty acids into neutral lipids, such as TGs and sterols, to store in the lipid core of the lipid droplets (Fig. 5) (130). The production of lipid droplets decreases the cellular lipid toxicity caused by excess lipids and maintains cell homeostasis (14). In addition, ROS is an important oxidative factor in cells, and excessive ROS can cause oxidative stress. ROS refers to a class of molecules derived from molecular oxygen and free radicals. As ROS contain an unpaired electron, they become a potent oxidant that reacts quickly with other pairs of electrons. ROS in cells are mainly derived from the mitochondria, which is a by-product of fatty acid oxidation, mainly in the form of hydrogen peroxide in the cytoplasm (14). Usually, the intracellular ROS levels in cells are high when the lipid content is also high (131). ROS are important signaling molecules that act as a ligands or activate multiple cellular signaling pathways, such as heat shock factor protein 1, NF- $\mathrm{kB}, \mathrm{p} 53$, PI3K-AKT and ERK/JNK/p38, thereby affecting cellular carbohydrate metabolism, mitochondrial function, apoptosis and necrosis, proliferation and cancer cell infiltration (132-135). At present, studies have found that ROS affect the formation and degradation of cellular lipids $(12,23,64,136)$. Increased ROS levels can damage mitochondria, reduce mitochondrial activity and activate c-Jun-N-terminal Kinase (JNK) and SREBP, which could lead to lipid droplet accumulation in glial cells (23). A decrease in mitochondrial activity further increases intracellular ROS levels, thereby further activating the SREBP pathway and promoting lipid droplet formation (Fig. 5) (137-139). In addition, studies have reported that ROS molecules regulate the recruitment of lipase to the surface of lipid droplets and the recognition of lipid droplets by autophagic vacuoles $(136,140)$. Some studies have shown that lipid droplets can protect cells from ROS-induced cell damage $(78,98,131,141)$. For example, Bailey et al (12) reported that ROS can oxidize phospholipid membranes to increase the content of 4-hydroxynonenal (HNE) (a product of lipid oxidation that causes protein damage) on cell the membrane, whereas 4-HNE can promote ROS production, which leads to positive feedback that causes cell damage. In this process, lipid droplets can re-distribute the oxidized lipids of membranes, thereby reducing the oxidized lipid content of the cell membrane and lowering the levels of 4-HNE to promote cell survival (Fig. 5) $(12,142)$. Lipid droplets can also resist cellular stress by interacting with other organelles. For example, by analyzing the traces of several organelles in cells under starvation and normal conditions, it can be observed that, in a state of starvation, the lipid droplets 
contact the mitochondria at a higher frequency and they are closer together (6), which is compatible with increased energy supply. For example, lipid droplets can bind to mitochondria, which promotes the utilization of lipids (6).

Caspase-12 serves an important role in the apoptosis-mediated ER stress pathway (143). Cells with a higher lipid droplet content have enhanced resistance against ROS and lipo-toxicity by decreasing the release of calcium ions from the ER and inhibiting the activation of caspase-12 mediated by ER stress. This is important for apoptosis. In the case of immunotherapy, the high levels of lipid droplets can recruit CRT (144), thereby blocking the transfer of CRT from the Golgi to the cell membrane (Fig. 5) (144). Low levels of CRT on the cell membrane inhibit the maturation of immature dendritic cells, as the maturation of immature dendritic cells is activated by the binding between CD91 on the surface of immature dendritic cells and CRT on the surface of cancer cells (99). Caspase- 8 is important for CRT exposure (145). However, lipid droplet accumulation leads to a downregulation of caspase-8, which causes a decrease in CRT exposure and prevents cancer cells from being recognized by immune cells (99). As aforementioned, the presence of COX-2 in the lipid droplets promotes the production of PGE2 (79), thereby producing an immunosuppressive environment (Fig. 5) (146). Furthermore, CIDEC can be recruited to the surface of the lipid droplet. The CIDEC amino acids 174-192 are lipophilic, allowing them to bind to lipid droplets. However, this domain also plays an important role in the interaction with caspase-9 $(147,148)$. Therefore, CIDEC binding to lipid droplets impacts the role of CIDEC in the apoptosis process (Fig. 5). A recent study showed that lipid droplets can be in contact with the mitochondria and transfer apoptosis-associated proteins, such as BAX, BCL-2 and BCL-Xl, from the surface of the mitochondria to the surface of the lipid. This process could prevent mitochondrial damage and inhibit apoptosis (Fig. 5) (149). Moreover, a study has shown that bacterial lipid droplets can bind to DNA via the surface protein, microorganism lipid droplet small protein (MLDS), which plays an important role in stabilizing bacterial genetic material and promotes the survival of bacteria under stress conditions (150). In addition, it is noteworthy that the nuclear inner membrane also engages in lipid synthesis activities and produces nuclear lipid droplets in eukaryotes, whereas nuclear lipid droplets regulate the synthesis of cellular phospholipids, and maintain cell membranes homeostasis (50). In summary, lipid droplets can enhance cell stress resistance, reduce stress-induced cell death, maintain cell homeostasis and promote cell survival by stabilizing excess free lipids. This provides cell membrane components and energy, re-distributes peroxidized lipids and inhibits caspase activation.

\section{Potential mechanism of lipid droplets regulating EGFR activation}

According to previous study investigating lipid droplets in lung cancer $(40,74,75)$, the mechanism of lipid droplet-mediated regulation of EGFR activation can be hypothesized. Lipid droplets can affect cellular ROS levels and energy metabolism signaling. On the one hand, ROS levels are decreased by lipid droplet formation. However, EGFR phosphorylation can be regulated by ROS levels. Decreased levels of ROS can activate
EGFR (151,152). Moreover, the EGFR/MEK/ERK pathway is also regulated by ROS levels. On the other hand, FASN can be activated by lipid droplet formation, especially in cancer cells. However, previous studies have reported that EGFR can be activated through FASN-dependent palmitoylation $(153,154)$, and this activation can be blocked by an FASN inhibitor, such as Orlistat (154). Lipid droplet accumulation contributes to the activation of EGFR by regulating ROS level and fatty acid synthase activity. Therefore, lipid droplets play an important role in regulating EGFR activation. The development of inhibitors of lipid droplets accumulation may be beneficial in regulating EGFR activation.

\section{Conclusions}

Lung cancer is one of the most common types of cancer worldwide, which accounted for $13.49 \%$ of total cancer cases in 2018, and the 5-year survival rate of lung cancer is only $18 \%$ (28). Several EGFR tyrosine kinase inhibitors (TKIs), including gefitinib, erlotinib, afatinib and osimertinib are used for the treatment of lung cancer; however, persistent drug resistance suppresses the cure rate $(29,30)$. Compared with healthy cells, cancer cells undergo a rearrangement of their metabolism, during which changes in lipid metabolism cause lipid droplets to accumulate. As highly dynamic organelles, lipid droplets participate in a variety of biological processes, especially the regulation of energy metabolism, cell proliferation, apoptosis, stress resistance, immune response and other processes associated with cancer cell proliferation $(1-3,9,80)$. Therefore, the role of lipid droplets cannot be ignored when investigating novel treatments for cancer. NSCLC tissues have higher lipid droplet content compared with para-cancerous tissues, and EGFR-TKI resistant cells contain more lipid droplets compared with non-resistant cells. Intracellular lipid droplets not only provide cell membrane phospholipid components for cancer cell proliferation but also provide a large supply of energy, which is especially important for cancer cells with rapid metabolism and proliferation. In addition, treatment with common chemotherapeutic drugs and TKI drugs (such as gefitinib) will further stimulate the formation of lipid droplets, and the accumulated lipid droplets will weaken the cytotoxicity of the drug and inhibit drug-mediated apoptosis, which affects the clinical treatment benefit. Furthermore, lipid droplets can inhibit ER stress and the activation of caspase- 8 and caspase-12. Lipid droplets can also recruit CRT, thereby inhibiting the transfer of CRT from the ER to the Golgi apparatus and cell membrane, which affects the recognition of cancer cells by immune cells. In addition, the presence of COX-2 on the surface of lipid droplets can promote the synthesis of PGE2, which interferes with the immune environment, and induces inhibition of the antitumor responses. The metabolic process of lipid synthesis and oxidation is enhanced in cancer cells, which causes a greater generation of ROS. However, lipid droplets can attenuate lipid peroxidation of cell membrane components and can remove proteins, such as Bcl-XL, BIK and BAK, which could induce apoptosis from the mitochondria by contact. Therefore, lipid droplets offer an important contribution to cell stress resistance and the maintenance of cell homeostasis.

There are currently no effective inhibitors of lipid droplet accumulation, but targets in the lipid droplet formation process 
have been identified resulting in inhibited lipid formation, such as some anti-inflammatory drugs, such as sulindac, celecoxib and aspirin (155-157). FASN is a rate-limiting enzyme in that functions in the de novo synthesis of lipids. The inhibitor TVB-3664 inhibits the de novo synthesis of fatty acids by targeting FASN $(158,159)$. In addition, inhibitors against SCD1, such as g-PPT, can reduce the synthesis of polyunsaturated fatty acids, thereby inhibiting the synthesis of TG and reducing lipid droplet content (40). The combination of g-PPT and gefitinib effectively reduces drug resistance and promotes the apoptosis of cancer cells (40). Therefore, in the future, a variety of lipid-targeting inhibitors, such as PLIN2-targeting inhibitors, should be developed, particularly as PLIN2 has an important role in the formation and stabilization of lipid droplets by regulating lipid droplet lipolysis and autophagy (160). By reducing the amount of lipid droplets in tumor cells, the protective effect of lipid droplets on cells can be impaired, and drug cytotoxicity and drug-mediated apoptosis can be promoted.

In general, in the treatment of drug-resistant NSCLC, a combined approach should be considered. Using drugs targeting lipid metabolism to reduce lipid droplet content would promote the sensitivity of tumor cells to drugs and enhance treatment effects.

\section{Acknowledgements}

The authors of the present study would like to thank Dr Yi Jin, from the College of Animal Science, Huazhong Agricultural University (Wuhan, China) for his help in researching the progress of lipid droplets and oxidative stress.

\section{Funding}

No funding was received.

\section{Availability of data and materials}

The datasets used and/or analyzed during the current study are available from the corresponding author on reasonable request.

\section{Authors' contributions}

CJ researched the topic literation, designed the study and drafted the initial manuscript. CJ and PY participated in writing and editing the manuscript critically. CJ and PY prepared the images. Both authors read and approved the final manuscript.

\section{Ethics approval and consent to participate}

Not applicable.

\section{Patient consent for publication}

Not applicable.

\section{Competing interests}

The authors declare that they have no competing interests.

\section{References}

1. Welte MA: Expanding roles for lipid droplets. Curr Biol 25: R470-R481, 2015.

2. Walther TC, Chung J and Farese RV Jr: Lipid Droplet Biogenesis. Annu Rev Cell Dev Biol 33: 491-510, 2017.

3. Wilfling F, Haas JT, Walther TC and Farese RV Jr: Lipid droplet biogenesis. Curr Opin Cell Biol 29: 39-45, 2014.

4. Cohen S, Valm AM and Lippincott-Schwartz J: Interacting organelles. Curr Opin Cell Biol 53: 84-91, 2018.

5. Olzmann JA and Carvalho P: Dynamics and functions of lipid droplets. Nat Rev Mol Cell Biol 20: 137-155, 2019.

6. Valm AM, Cohen S, Legant WR, Melunis J, Hershberg U, Wait E, Cohen AR, Davidson MW, Betzig E and Lippincott-Schwartz J: Applying systems-level spectral imaging and analysis to reveal the organelle interactome. Nature 546: 162-167, 2017.

7. Fujimoto T, Ohsaki Y, Cheng J, Suzuki M and Shinohara Y: Lipid droplets: A classic organelle with new outfits. Histochem Cell Biol 130: 263-279, 2008.

8. Salo VT and Ikonen E: Moving out but keeping in touch: Contacts between endoplasmic reticulum and lipid droplets. Curr Opin Cell Biol 57: 64-70, 2019.

9. Schuldiner M and Bohnert M: A different kind of love - lipid droplet contact sites. Biochim Biophys Acta Mol Cell Biol Lipids 1862B: 1188-1196, 2017.

10. Welte MA and Gould AP: Lipid droplet functions beyond energy storage. Biochim Biophys Acta Mol Cell Biol Lipids 186B: 1260-1272, 2017.

11. Karagiannis F, Masouleh SK, Wunderling K, Surendar J, Schmitt V, Kazakov A, Michla M, Hölzel M, Thiele C and Wilhelm C: Lipid-Droplet Formation Drives Pathogenic Group 2 Innate Lymphoid Cells in Airway Inflammation. Immunity 52: 620-634 e626, 2020.

12. Bailey AP, Koster G, Guillermier C, Hirst EM, MacRae JI, Lechene CP, Postle AD and Gould AP: Antioxidant Role for Lipid Droplets in a Stem Cell Niche of Drosophila. Cell 163: 340-353, 2015.

13. Rambold AS, Cohen S and Lippincott-Schwartz J: Fatty acid trafficking in starved cells: Regulation by lipid droplet lipolysis, autophagy, and mitochondrial fusion dynamics. Dev Cell 32: 678-692, 2015.

14. Jarc E and Petan T: Lipid Droplets and the Management of Cellular Stress. Yale J Biol Med 92: 435-452, 2019.

15. Pavlova NN and Thompson CB: The Emerging Hallmarks of Cancer Metabolism. Cell Metab 23: 27-47, 2016.

16. Sciacovelli $M$ and Frezza C: Metabolic reprogramming and epithelial-to-mesenchymal transition in cancer. FEBS J 284: 3132-3144, 2017.

17. Ward PS and Thompson CB: Metabolic reprogramming: A cancer hallmark even warburg did not anticipate. Cancer Cell 21: 297-308, 2012.

18. Ou J, Miao H, Ma Y, Guo F, Deng J, Wei X, Zhou J, Xie G, Shi H, Xue B, et al: Loss of abhd5 promotes colorectal tumor development and progression by inducing aerobic glycolysis and epithelial-mesenchymal transition. Cell Rep 9: 1798-1811, 2014.

19. Zagani R, El-Assaad W, Gamache I and Teodoro JG: Inhibition of adipose triglyceride lipase (ATGL) by the putative tumor suppressor G0S2 or a small molecule inhibitor attenuates the growth of cancer cells. Oncotarget 6: 28282-28295, 2015.

20. Hirsch HA, Iliopoulos D, Joshi A, Zhang Y, Jaeger SA, Bulyk M, Tsichlis PN, Shirley Liu X and Struhl K: A transcriptional signature and common gene networks link cancer with lipid metabolism and diverse human diseases. Cancer Cell 17: 348-361, 2010.

21. Patterson AD, Maurhofer O, Beyoglu D, Lanz C, Krausz KW, Pabst T, Gonzalez FJ, Dufour JF and Idle JR: Aberrant lipid metabolism in hepatocellular carcinoma revealed by plasma metabolomics and lipid profiling. Cancer Res 71: 6590-6600, 2011.

22. Ueno M, Shen WJ, Patel S, Greenberg AS, Azhar S and Kraemer FB: Fat-specific protein 27 modulates nuclear factor of activated T cells 5 and the cellular response to stress. J Lipid Res 54: 734-743, 2013.

23. Liu L, Zhang K, Sandoval H, Yamamoto S, Jaiswal M, Sanz E, Li Z, Hui J, Graham BH, Quintana A, et al: Glial lipid droplets and ROS induced by mitochondrial defects promote neurodegeneration. Cell 160: 177-190, 2015.

24. Covington JD, Coen PM, Burk DH, Obanda DN, Ebenezer PJ, Tam CS, Goodpaster BH, Ravussin E and Bajpeyi S: Intramyocellular Lipid Droplet Size Rather than Total Lipid Content Is Related to Insulin Sensitivity after 8 Weeks of Overfeeding. Diabetes 64: A11-A11, 2015 
25. Nielsen J, Christensen AE, Nellemann B and Christensen B Lipid droplet size and location in human skeletal muscle fibers are associated with insulin sensitivity. Am J Physiol Endocrinol Metab 313: E721-E730, 2017.

26. Satapati S, Kucejova B, Duarte JAG, Fletcher JA, Reynolds L, Sunny NE, He T, Nair LA, Livingston KA, Fu X, et al: Mitochondrial metabolism mediates oxidative stress and inflammation in fatty liver. J Clin Invest 125: 4447-4462, 2015.

27. Kim HY, Kwon WY, Kim YA, Oh YJ, Yoo SH, Lee MH, Bae JY, Kim JM and Yoo YH: Polychlorinated biphenyls exposure-induced insulin resistance is mediated by lipid droplet enlargement through Fsp27. Arch Toxicol 91: 2353-2363, 2017.

28. Siegel RL, Miller KD and Jemal A: Cancer statistics, 2018. CA Cancer J Clin 68: 7-30, 2018

29. Remon J, Morán T, Majem M, Reguart N, Dalmau E, Márquez-Medina D and Lianes P: Acquired resistance to epidermal growth factor receptor tyrosine kinase inhibitors in EGFR-mutant non-small cell lung cancer: A new era begins. Cancer Treat Rev 40: 93-101, 2014.

30. Juchum M, Günther M and Laufer SA: Fighting cancer drug resistance: Opportunities and challenges for mutation-specific EGFR inhibitors. Drug Resist Updat 20: 12-28, 2015.

31. Lynch TJ, Bell DW, Sordella R, Gurubhagavatula S, Okimoto RA, Brannigan BW, Harris PL, Haserlat SM, Supko JG, Haluska FG, et al: Activating mutations in the epidermal growth factor receptor underlying responsiveness of non-small-cell lung cancer to gefitinib. N Engl J Med 350: 2129-2139, 2004.

32. Paez JG, Jänne PA, Lee JC, Tracy S, Greulich H, Gabriel S, Herman P, Kaye FJ, Lindeman N, Boggon TJ, et al: EGFR mutations in lung cancer: Correlation with clinical response to gefitinib therapy. Science 304: 1497-1500, 2004

33. Pao W, Miller V, Zakowski M, Doherty J, Politi K, Sarkaria I, Singh B, Heelan R, Rusch V, Fulton L, et al: EGF receptor gene mutations are common in lung cancers from 'never smokers' and are associated with sensitivity of tumors to gefitinib and erlotinib. Proc Natl Acad Sci USA 101: 13306-13311, 2004.

34. Wen C, Xu G, He S, Huang Y, Shi J, Wu L and Zhou H: Screening Circular RNAs Related to Acquired Gefitinib Resistance in Non-small Cell Lung Cancer Cell Lines. J Cancer 11: 3816-3826, 2020.

35. Lin Y, Higashisaka K, Shintani T, Maki A, Hanamuro S, Haga Y, Maeda S, Tsujino H, Nagano K, Fujio Y, et al: Progesterone receptor membrane component 1 leads to erlotinib resistance, initiating crosstalk of $\mathrm{Wnt} / \beta$-catenin and $\mathrm{NF}-\kappa \mathrm{B}$ pathways, in lung adenocarcinoma cells. Sci Rep 10: 4748, 2020.

36. Chen C, Liu WR, Zhang B, Zhang LM, Li CG, Liu C, Zhang H, Huo YS, Ma YC, Tian PF, et al: IncRNA H19 downregulation confers erlotinib resistance through upregulation of PKM2 and phosphorylation of AKT in EGFR-mutant lung cancers. Cancer Lett 486: 58-70, 2020.

37. Wu JY, Wu SG, Yang CH, Chang YL, Chang YC, Hsu YC, Shih JY and Yang PC: Comparison of gefitinib and erlotinib in advanced NSCLC and the effect of EGFR mutations. Lung Cancer 72: 205-212, 2011

38. Lee CK, Brown C, Gralla RJ, Hirsh V, Thongprasert S, Tsai CM, Tan EH, Ho JC, Chu T, Zaatar A, et al: Impact of EGFR inhibitor in non-small cell lung cancer on progression-free and overall survival: A meta-analysis. J Natl Cancer Inst 105: 595-605, 2013.

39. Kasahara K, Arao T, Sakai K, Matsumoto K, Sakai A, Kimura H, Sone T, Horiike A, Nishio M, Ohira T, et al: Impact of serum hepatocyte growth factor on treatment response to epidermal growth factor receptor tyrosine kinase inhibitors in patients with non-smal cell lung adenocarcinoma. Clin Cancer Res 16: 4616-4624, 2010.

40. Huang Q, Wang Q, Li D, Wei X, Jia Y, Zhang Z, Ai B, Cao X Guo T and Liao Y: Co-administration of 20(S)-protopanaxatrio (g-PPT) and EGFR-TKI overcomes EGFR-TKI resistance by decreasing SCD1 induced lipid accumulation in non-small cell lung cancer. J Exp Clin Canc Res 38: 129, 2019.

41. Grillitsch K, Connerth M, Köfeler H, Arrey TN, Rietschel B, Wagner B, Karas M and Daum G: Lipid particles/droplets of the yeast Saccharomyces cerevisiae revisited: Lipidome meets proteome. Biochim Biophys Acta 1811: 1165-1176, 2011.

42. Bartz R, Li WH, Venables B, Zehmer JK, Roth MR, Welti R, Anderson RG, Liu P and Chapman KD: Lipidomics reveals that adiposomes store ether lipids and mediate phospholipid traffic. J Lipid Res 48: 837-847, 2007

43. Vrablik TL, Petyuk VA, Larson EM, Smith RD and Watts JL: Lipidomic and proteomic analysis of Caenorhabditis elegans lipid droplets and identification of ACS-4 as a lipid droplet-associated protein. Biochim Biophys Acta 1851: 1337-1345, 2015.
44. Prévost C, Sharp ME, Kory N, Lin Q, Voth GA, Farese RV Jr and Walther TC: Mechanism and Determinants of Amphipathic Helix-Containing Protein Targeting to Lipid Droplets. Dev Cell 44: 73-86, 2018

45. Zhao Y, Chen Z, Wu Y, Tsukui T, Ma X, Zhang X, Chiba H and Hui SP: Separating and Profiling Phosphatidylcholines and Triglycerides from Single Cellular Lipid Droplet by In-Tip Solvent Microextraction Mass Spectrometry. Anal Chem 91: 4466-4471, 2019

46. Wilfling F, Thiam AR, Olarte MJ, Wang J, Beck R, Gould TJ, Allgeyer ES, Pincet F, Bewersdorf J, Farese RV Jr and Walther TC: Arf1/COPI machinery acts directly on lipid droplets and enables their connection to the ER for protein targeting. Elife 3: e01607, 2014.

47. Wang H, Becuwe M, Housden BE, Chitraju C, Porras AJ, Graham MM, Liu XN, Thiam AR, Savage DB, Agarwal AK, et al: Seipin is required for converting nascent to mature lipid droplets. Elife 5: e16582, 2016.

48. Sturley SL and Hussain MM: Lipid droplet formation on opposing sides of the endoplasmic reticulum. J Lipid Res 53: 1800-1810, 2012

49. Gibbons GF, Islam K and Pease RJ: Mobilisation of triacylglycerol stores. Biochim Biophys Acta 1483: 37-57, 2000.

50. Romanauska A and Kohler A: The Inner Nuclear Membrane Is a Metabolically Active Territory that Generates Nuclear Lipid Droplets. Cell 174: 700-715, 2018.

51. Soltysik K, Ohsaki Y, Tatematsu T, Cheng JL and Fujimoto T: Nuclear lipid droplets derive from a lipoprotein precursor and regulate phosphatidylcholine synthesis. Nat Commun 10: 473, 2019.

52. Liao Y, Tham DKL, Liang FX, Chang J, Wei Y, Sudhir PR, Sall J, Ren SJ, Chicote JU, Arnold LL, et al: Mitochondrial lipid droplet formation as a detoxification mechanism to sequester and degrade excessive urothelial membranes. Mol Biol Cell 30: 2969-2984, 2019.

53. Zimmermann R, Strauss JG, Haemmerle G, Schoiswohl G, Birner-Gruenberger R, Riederer M, Lass A, Neuberger G, Eisenhaber F, Hermetter A, et al: Fat mobilization in adipose tissue is promoted by adipose triglyceride lipase. Science 306 : 1383-1386, 2004

54. Reid BN, Ables GP, Otlivanchik OA, Schoiswohl G, Zechner R, Blaner WS, Goldberg IJ, Schwabe RF, Chua SC Jr and Huang LS: Hepatic overexpression of hormone-sensitive lipase and adipose triglyceride lipase promotes fatty acid oxidation, stimulates direct release of free fatty acids, and ameliorates steatosis. J Biol Chem 283: 13087-13099, 2008.

55. Holm C, Kirchgessner TG, Svenson KL, Fredrikson G, Nilsson S, Miller CG, Shively JE, Heinzmann C, Sparkes RS, Mohandas T, et al: Hormone-sensitive lipase: Sequence, expression, and chromosomal localization to 19 cent-q13.3. Science 241: 1503-1506, 1988

56. Karlsson M, Contreras JA, Hellman U, Tornqvist H and Holm C: cDNA cloning, tissue distribution, and identification of the catalytic triad of monoglyceride lipase. Evolutionary relationship to esterases, lysophospholipases, and haloperoxidases. J Biol Chem 272: 27218-27223, 1997.

57. Young SG and Zechner R: Biochemistry and pathophysiology of intravascular and intracellular lipolysis. Genes Dev 27: 459-484, 2013.

58. Zechner R, Zimmermann R, Eichmann TO, Kohlwein SD, Haemmerle G, Lass A and Madeo F: FAT SIGNALS--lipases and lipolysis in lipid metabolism and signaling. Cell Metab 15: 279-291, 2012.

59. Jaworski K, Sarkadi-Nagy E, Duncan RE, Ahmadian M and Sul HS: Regulation of triglyceride metabolism. IV. Hormonal regulation of lipolysis in adipose tissue. Am J Physiol Gastrointest Liver Physiol 293: G1-G4, 2007.

60. Settembre C and Ballabio A: Lysosome: Regulator of lipid degradation pathways. Trends Cell Biol 24: 743-750, 2014.

61. Aboumrad MH, Horn RC Jr and Fine G: Lipid-secreting mammary carcinoma. Report of a case associated with Paget's disease of the nipple. Cancer 16: 521-525, 1963.

62. Ramos CV and Taylor HB: Lipid-rich carcinoma of the breast. A clinicopathologic analysis of 13 examples. Cancer 33: 812-819, 1974.

63. Warburg O: On the origin of cancer cells. Science 123: 309-314, 1956.

64. Huang WC, Li X, Liu J, Lin J and Chung LWK: Activation of androgen receptor, lipogenesis, and oxidative stress converged by SREBP-1 is responsible for regulating growth and progression of prostate cancer cells. Mol Cancer Res 10: 133-142, 2012.

65. Hanahan D and Weinberg RA: Hallmarks of cancer: The next generation. Cell 144: 646-674, 2011. 
66. Baenke F, Peck B, Miess H and Schulze A: Hooked on fat: The role of lipid synthesis in cancer metabolism and tumour development. Dis Model Mech 6: 1353-1363, 2013.

67. Zaytseva YY, Harris JW, Mitov MI, Kim JT, Butterfield DA, Lee EY, Weiss HL, Gao T and Evers BM: Increased expression of fatty acid synthase provides a survival advantage to colorectal cancer cells via upregulation of cellular respiration. Oncotarget 6: 18891-18904, 2015.

68. Cai Y, Crowther J, Pastor T, Abbasi Asbagh L, Baietti MF, De Troyer M, Vazquez I, Talebi A, Renzi F, Dehairs J, et al: Loss of Chromosome 8p Governs Tumor Progression and Drug Response by Altering Lipid Metabolism. Cancer Cell 29: 751-766, 2016.

69. Röhrig F and Schulze A: The multifaceted roles of fatty acid synthesis in cancer. Nat Rev Cancer 16: 732-749, 2016.

70. Porstmann T, Santos CR, Griffiths B, Cully M, Wu M, Leevers S, Griffiths JR, Chung YL and Schulze A: SREBP activity is regulated by $\mathrm{mTORC} 1$ and contributes to Akt-dependent cell growth. Cell Metab 8: 224-236, 2008.

71. Liu Y: Fatty acid oxidation is a dominant bioenergetic pathway in prostate cancer. Prostate Cancer Prostatic Dis 9: 230-234, 2006.

72. Hager MH, Solomon KR and Freeman MR: The role of cholesterol in prostate cancer. Curr Opin Clin Nutr Metab Care 9: 379-385, 2006.

73. Wang H, Xi Q and Wu G: Fatty acid synthase regulates invasion and metastasis of colorectal cancer via Wnt signaling pathway. Cancer Med 5: 1599-1606, 2016.

74. Gansler TS, Hardman W III, Hunt DA, Schaffel S and Hennigar RA: Increased expression of fatty acid synthase (OA-519) in ovarian neoplasms predicts shorter survival. Hum Pathol 28: 686-692, 1997.

75. Fujimoto M, Yoshizawa A, Sumiyoshi S, Sonobe M, Menju T, Hirata M, Momose M,Date H and Haga H: Adipophilin expression in lung adenocarcinoma is associated with apocrine-like features and poor clinical prognosis: An immunohistochemical study of 328 cases. Histopathology 70: 232-241, 2017.

76. Zhang XD, Li W, Zhang N, Hou YL, Niu ZQ, Zhong YJ, Zhang YP and Yang SY: Identification of adipophilin as a potential diagnostic tumor marker for lung adenocarcinoma. Int J Clin Exp Med 7: 1190-1196, 2014

77. Rak S, De Zan T, Stefulj J, Kosović M, Gamulin O and Osmak M: FTIR spectroscopy reveals lipid droplets in drug resistant laryngeal carcinoma cells through detection of increased ester vibrational bands intensity. Analyst (Lond) 139: 3407-3415, 2014.

78. Qiu B, Ackerman D, Sanchez DJ, Li B, Ochocki JD, Grazioli A Bobrovnikova-Marjon E, Diehl JA, Keith B and Simon MC: HIF $2 \alpha$-Dependent Lipid Storage Promotes Endoplasmic Reticulum Homeostasis in Clear-Cell Renal Cell Carcinoma. Cancer Discov 5: 652-667, 2015

79. Accioly MT, Pacheco P, Maya-Monteiro CM, Carrossini N, Robbs BK, Oliveira SS, Kaufmann C, Morgado-Diaz JA, Bozza PT and Viola JP: Lipid bodies are reservoirs of cyclooxygenase-2 and sites of prostaglandin-E2 synthesis in colon cancer cells. Cancer Res 68: 1732-1740, 2008.

80. Bozza PT and Viola JP: Lipid droplets in inflammation and cancer. Prostaglandins Leukot Essent Fatty Acids 82: 243-250, 2010

81. Nieva C, Marro M, Santana-Codina N, Rao S, Petrov D and Sierra A: The lipid phenotype of breast cancer cells characterized by Raman microspectroscopy: Towards a stratification of malignancy. PLoS One 7: e46456, 2012.

82. Fujimoto T, Kogo H, Ishiguro K, Tauchi K and Nomura R: Caveolin-2 is targeted to lipid droplets, a new 'membrane domain' in the cell. J Cell Biol 152: 1079-1085, 2001.

83. Yu W, Bozza PT, Tzizik DM, Gray JP, Cassara J, Dvorak AM and Weller PF: Co-compartmentalization of MAP kinases and cytosolic phospholipase A2 at cytoplasmic arachidonate-rich lipid bodies. Am J Pathol 152: 759-769, 1998

84. Yu W,Cassara J and Weller PF: Phosphatidylinositide 3-kinase localizes to cytoplasmic lipid bodies in human polymorphonuclear leukocytes and other myeloid-derived cells. Blood 95: 1078-1085, 2000.

85. Coussens LM and Werb Z: Inflammation and cancer. Nature 420: $860-867,2002$

86. Elinav E, Nowarski R, Thaiss CA, Hu B, Jin C and Flavell RA Inflammation-induced cancer: Crosstalk between tumours, immune cells and microorganisms. Nat Rev Cancer 13: 759-771, 2013.

87. Melo RCN and Weller PF: Lipid droplets in leukocytes: Organelles linked to inflammatory responses. Exp Cell Res 340: 193-197, 2016.

88. HellerS, Cable C,Penrose H,Makboul R,Biswas D, Cabe M,Crawford SE and Savkovic SD: Intestinal inflammation requires FOXO3 and prostaglandin E2-dependent lipogenesis and elevated lipid droplets. Am J Physiol Gastrointest Liver Physiol 310: G844-G854, 2016.
89. Rigas B, Goldman IS and Levine L: Altered eicosanoid levels in human colon cancer. J Lab Clin Med 122: 518-523, 1993.

90. Wang D and Dubois RN: Cyclooxygenase-2: A potential target in breast cancer. Semin Oncol 31 (Suppl 3): 64-73, 2004.

91. Hambek M, Baghi M, Wagenblast J, Schmitt J, Baumann H and Knecht R: Inverse correlation between serum PGE2 and T classification in head and neck cancer. Head Neck 29 (Spec): 244-248, 2007.

92. McLemore TL, Hubbard WC, Litterst CL, Liu MC, Miller S, McMahon NA, Eggleston JC and Boyd MR: Profiles of prostaglandin biosynthesis in normal lung and tumor tissue from lung cancer patients. Cancer Res 48: 3140-3147, 1988.

93. Yan M, Myung SJ, Fink SP, Lawrence E, Lutterbaugh J, Yang P, Zhou X, Liu D, Rerko RM, Willis J, et al: 15-Hydroxyprostaglandin dehydrogenase inactivation as a mechanism of resistance to celecoxib chemoprevention of colon tumors. Proc Natl Acad Sci USA 106: 9409-9413, 2009.

94. Martinez-Lopez N and Singh R: Autophagy and Lipid Droplets in the Liver. Annu Rev Nutr 35: 215-237, 2015

95. Schulze RJ, Sathyanarayan A and Mashek DG: Breaking fat: The regulation and mechanisms of lipophagy. Biochim Biophys Acta Mol Cell Biol Lipids 1862B: 1178-1187, 2017.

96.Zechner R, Madeo F and Kratky D: Cytosolic lipolysis and lipophagy: Two sides of the same coin. Nat Rev Mol Cell Biol 18: 671-684, 2017

97. Herms A, Bosch M, Reddy BJ, Schieber NL, Fajardo A, Rupérez C, Fernández-Vidal A, Ferguson C, Rentero C, Tebar F, et al: AMPK activation promotes lipid droplet dispersion on detyrosinated microtubules to increase mitochondrial fatty acid oxidation. Nat Commun 6: 7176, 2015.

98. Cabodevilla AG, Sánchez-Caballero L, Nintou E, Boiadjieva VG, Picatoste F, Gubern A and Claro E: Cell survival during complete nutrient deprivation depends on lipid droplet-fueled $\beta$-oxidation of fatty acids. J Biol Chem 288: 27777-27788, 2013.

99. Cotte AK, Aires V, Fredon M, Limagne E, Derangère V, Thibaudin M, Humblin E, Scagliarini A, de Barros JP, Hillon $\mathrm{P}$, et al: Lysophosphatidylcholine acyltransferase 2-mediated lipid droplet production supports colorectal cancer chemoresistance. Nat Commun 9: 322, 2018

100. Penrose H, Heller S, Cable C, Makboul R, Chadalawada G, Chen Y, Crawford SE and Savkovic SD: Epidermal growth factor receptor mediated proliferation depends on increased lipid droplet density regulated via a negative regulatory loop with FOXO3/Sirtuin6. Biochem Biophys Res Commun 469: 370-376, 2016

101. Müller MR and Rao A: NFAT, immunity and cancer: A transcription factor comes of age. Nat Rev Immunol 10: 645-656, 2010.

102. Jauliac S, López-Rodriguez C, Shaw LM, Brown LF, Rao A and Toker A: The role of NFAT transcription factors in integrin-mediated carcinoma invasion. Nat Cell Biol 4: 540-544, 2002.

103. Germann S, Gratadou L, Zonta E, Dardenne E, Gaudineau B, Fougère M, Samaan S, Dutertre M, Jauliac S and Auboeuf D: Dual role of the ddx $5 /$ ddx 17 RNA helicases in the control of the pro-migratory NFAT5 transcription factor. Oncogene 31: 4536-4549, 2012.

104. Chen M, Sinha M, Luxon BA, Bresnick AR and O'Connor KL: Integrin alpha6beta4 controls the expression of genes associated with cell motility, invasion, and metastasis, including S100A4/metastasin. J Biol Chem 284: 1484-1494, 2009.

105. Kim DH, Kim KS and Ramakrishna S: NFAT5 promotes in vivo development of murine melanoma metastasis. Biochem Biophys Res Commun 505: 748-754, 2018.

106. Guo K and Jin F: NFAT5 promotes proliferation and migration of lung adenocarcinoma cells in part through regulating AQP5 expression. Biochem Biophys Res Commun 465: 644-649, 2015

107. Kuper C, Beck FX and Neuhofer W: NFAT5-mediated expression of S100A4 contributes to proliferation and migration of renal carcinoma cells. Front Physiol 5: 293, 2014.

108. Meng X, Li Z, Zhou S, Xiao S and Yu P: miR-194 suppresses high glucose-induced non-small cell lung cancer cell progression by targeting NFAT5. Thorac Cancer 10: 1051-1059, 2019.

109. Tomin T,FritzK, GindlhuberJ,WaldherrL,PucherB,ThallingerGG, Nomura DK, Schittmayer M and Birner-Gruenberger R: Deletion of Adipose Triglyceride Lipase Links Triacylglycerol Accumulation to a More-Aggressive Phenotype in A549 Lung Carcinoma Cells. J Proteome Res 17: 1415-1425, 2018.

110. Zhang J, Song F, Zhao X, Jiang H, Wu X, Wang B, Zhou M, Tian M, Shi B, Wang H, et al: EGFR modulates monounsaturated fatty acid synthesis through phosphorylation of SCD1 in lung cancer. Mol Cancer 16: 127, 2017. 
111. Makinoshima H, Takita M, Matsumoto S, Yagishita A, Owada S, Esumi H and Tsuchihara K: Epidermal growth factor receptor (EGFR) signaling regulates global metabolic pathways in EGFR-mutated lung adenocarcinoma. J Biol Chem 289: 20813-20823, 2014.

112. De Rosa V, Iommelli F, Monti M, Fonti R, Votta G, Stoppelli MP and Del Vecchio S: Reversal of Warburg Effect and Reactivation of Oxidative Phosphorylation by Differential Inhibition of EGFR Signaling Pathways in Non-Small Cell Lung Cancer. Clin Cancer Res 21: 5110-5120, 2015.

113.Liu Y, Liu S, Wu C, Huang W, Xu B, Lian S, Wang L, Yue S, Chen N and Zhu Z: PD-1-Mediated PI3K/Akt/mTOR, Caspase 9/Caspase 3 and ERK Pathways Are Involved in Regulating the Apoptosis and Proliferation of $\mathrm{CD}^{+}{ }^{+}$and $\mathrm{CD} 8{ }^{+}$ T Cells During BVDV Infection in vitro. Front Immunol 11: 467, 2020

114. Amri J, Molaee N and Karami H; J A: Up-Regulation of MiRNA-125a-5p Inhibits Cell Proliferation and Increases EGFR-TKI Induced Apoptosis in Lung Cancer Cells. Asian Pac J Cancer Prev 20: 3361-3367, 2019.

115.Efeyan A, Comb WC and Sabatini DM: Nutrient-sensing mechanisms and pathways. Nature 517: 302-310, 2015.

116. Hardie DG, Ross FA and Hawley SA: AMPK: A nutrient and energy sensor that maintains energy homeostasis. Nat Rev Mol Cell Biol 13: 251-262, 2012.

117. Garcia D and Shaw RJ: AMPK: Mechanisms of Cellular Energy Sensing and Restoration of Metabolic Balance. Mol Cell 66: 789-800, 2017.

118. Aramburu J, Ortells MC, Tejedor S, Buxade $\mathrm{M}$ and Lopez-Rodriguez C: Transcriptional regulation of the stress response by mTOR. Sci Signal 7: re2, 2014.

119. Muoio DM, Seefeld K, Witters LA and Coleman RA AMP-activated kinase reciprocally regulates triacylglycerol synthesis and fatty acid oxidation in liver and muscle: Evidence that sn-glycerol-3-phosphate acyltransferase is a novel target. Biochem J 338: 783-791, 1999.

120.Jeon SM, Chandel NS and Hay N: AMPK regulates NADPH homeostasis to promote tumour cell survival during energy stress. Nature 485: 661- 665, 2012.

121. Wendel AA, Lewin TM and Coleman RA: Glycerol-3-phosphate acyltransferases: Rate limiting enzymes of triacylglycerol biosynthesis. Biochim Biophys Acta 1791: 501-506, 2009.

122. Düvel K, Yecies JL, Menon S, Raman P, Lipovsky AI, Souza AL, Triantafellow E, Ma Q, Gorski R, Cleaver S, et al: Activation of a metabolic gene regulatory network downstream of mTOR complex 1. Mol Cell 39: 171-183, 2010.

123. Yecies JL, Zhang HH, Menon S, Liu S, Yecies D, Lipovsky AI, Gorgun C, Kwiatkowski DJ, Hotamisligil GS, Lee CH, et al: Akt stimulates hepatic SREBP1c and lipogenesis through parallel mTORC1-dependent and independent pathways. Cell Metab 14: $21-32,2011$

124. Owen JL, Zhang Y, Bae SH, Farooqi MS, Liang G, Hammer RE, Goldstein JL and Brown MS: Insulin stimulation of SREBP-1c processing in transgenic rat hepatocytes requires p70 S6-kinase. Proc Natl Acad Sci USA 109: 16184-16189, 2012.

125. Nguyen TB, Louie SM, Daniele JR, Tran Q, Dillin A, Zoncu R Nomura DK and Olzmann JA: DGAT1-Dependent Lipid Droplet Biogenesis Protects Mitochondrial Function during Starvation-Induced Autophagy. Dev Cell 42: 9-21, 2017.

126. Seo AY, Lau PW, Feliciano D, Sengupta P, Gros MAL, Cinquin B, Larabell CA and Lippincott-Schwartz J: AMPK and vacuole-associated Atg14p orchestrate mu-lipophagy for energy production and long-term survival under glucose starvation. Elife 6: e21690, 2017.

127. Henne WM, Reese ML and Goodman JM: The assembly of lipid droplets and their roles in challenged cells. EMBO J 37: e98947, 2018

128. Hariri H, Rogers S, Ugrankar R, Liu YL, Feathers JR and Henne WM: Lipid droplet biogenesis is spatially coordinated at ER-vacuole contacts under nutritional stress. EMBO Rep 19: $57-72,2018$

129. Schaffer JE: Lipotoxicity: When tissues overeat. Curr Opin Lipidol 14: 281-287, 2003.

130.Petan T, Jarc E and Jusovic M: Lipid Droplets in Cancer: Guardians of Fat in a Stressful World. Molecules 23: 1941, 2018

131.Herms A, Bosch M, Ariotti N, Reddy BJ, Fajardo A, Fernández-Vidal A, Alvarez-Guaita A, Fernández-Rojo MA, Rentero C, Tebar F, et al: Cell-to-cell heterogeneity in lipid droplets suggests a mechanism to reduce lipotoxicity. Curr Biol 23: 1489-1496, 2013.
132. Perillo B, Di Donato M, Pezone A, Di Zazzo E, Giovannelli P, Galasso G, Castoria G and Migliaccio A: ROS in cancer therapy: The bright side of the moon. Exp Mol Med 52: 192-203, 2020.

133. Li R, Jia Z and Trush MA: Defining ROS in Biology and Medicine. React Oxyg Species (Apex) 1: 9-21, 2016.

134. Ramzan R, Vogt S and Kadenbach B: Stress-mediated generation of deleterious ROS in healthy individuals - role of cytochrome $c$ oxidase. J Mol Med (Berl) 98: 651-657, 2020.

135. Yang S and Lian G: ROS and diseases: Role in metabolism and energy supply. Mol Cell Biochem 467: 1-12, 2020.

136. Zhang Z, Zhao S, Yao Z, Wang L, Shao J, Chen A, Zhang F and Zheng S: Autophagy regulates turnover of lipid droplets via ROS-dependent Rab25 activation in hepatic stellate cell. Redox Biol 11: 322-334, 2017

137. Müller G, Wied S,Jung C and Over S: Hydrogen peroxide-induced translocation of glycolipid-anchored (c)AMP-hydrolases to lipid droplets mediates inhibition of lipolysis in rat adipocytes. Br J Pharmacol 154: 901-913, 2008.

138. Blas-García A, Apostolova N, Ballesteros D, Monleón D, Morales JM, Rocha M, Victor VM and Esplugues JV: Inhibition of mitochondrial function by efavirenz increases lipid content in hepatic cells. Hepatology 52: 115-125, 2010.

139. Sekiya M, Hiraishi A, Touyama M and Sakamoto K: Oxidative stress induced lipid accumulation via SREBP1c activation in HepG2 cells. Biochem Biophys Res Commun 375: 602-607, 2008.

140. Krawczyk SA, Haller JF, Ferrante T, Zoeller RA and Corkey BE: Reactive Oxygen Species Facilitate Translocation of Hormone Sensitive Lipase to the Lipid Droplet During Lipolysis in Human Differentiated Adipocytes. Plos One 7: e34904, 2012.

141. Velázquez AP, Tatsuta T, Ghillebert R, Drescher I and Graef M Lipid droplet-mediated ER homeostasis regulates autophagy and cell survival during starvation. J Cell Biol 212: 621-631, 2016.

142. Welte MA: How Brain Fat Conquers Stress. Cell 163: 269-270, 2015

143. Szegezdi E, Fitzgerald U and Samali A: Caspase-12 and ER-stress-mediated apoptosis: The story so far. Ann N Y Acad Sci 1010: 186-194, 2003.

144. Turró S, Ingelmo-Torres M,Estanyol JM, Tebar F,Fernández MA, Albor CV, Gaus K, Grewal T, Enrich C and Pol A: Identification and characterization of associated with lipid droplet protein 1: A novel membrane-associated protein that resides on hepatic lipid droplets. Traffic 7: 1254-1269, 2006.

145. Panaretakis T, Kepp O, Brockmeier U, Tesniere A, Bjorklund AC, Chapman DC, Durchschlag M,Joza N, Pierron G, van Endert P, et al: Mechanisms of pre-apoptotic calreticulin exposure in immunogenic cell death. EMBO J 28: 578-590, 2009.

146. Kalinski P: Regulation of immune responses by prostaglandin E2. J Immunol 188: 21-28, 2012

147. Gao G, Chen FJ, Zhou L, Su L, Xu D, Xu L and Li P: Control of lipid droplet fusion and growth by CIDE family proteins. Biochim Biophys Acta Mol Cell Biol Lipids 1862B: 1197-1204, 2017.

148. Liu K, Zhou S, Kim JY, Tillison K, Majors D, Rearick D, Lee JH, Fernandez-Boyanapalli RF, Barricklow K, Houston MS, et al: Functional analysis of FSP27 protein regions for lipid droplet localization, caspase-dependent apoptosis, and dimerization with CIDEA. Am J Physiol Endocrinol Metab 297: E1395-E1413, 2009.

149. Bischof J, Salzmann M, Streubel MK, Hasek J, Geltinger F, Duschl J, Bresgen N, Briza P, Haskova D, Lejskova R, et al: Clearing the outer mitochondrial membrane from harmful proteins via lipid droplets. Cell Death Discov 3: 17016, 2017.

150. Zhang C, Yang L, Ding Y, Wang Y, Lan L, Ma Q, Chi X, Wei P, Zhao Y, Steinbüchel A, et al: Bacterial lipid droplets bind to DNA via an intermediary protein that enhances survival under stress. Nat Commun 8: 15979, 2017.

151. Wang G, Li Y, Yang Z, Xu W, Yang Y and Tan X: ROS mediated EGFR/MEK/ERK/HIF-1 $\alpha$ Loop Regulates Glucose metabolism in pancreatic cancer. Biochem Biophys Res Commun 500: 873-878, 2018

152. Wang TH, Chen CC, Huang KY, Shih YM and Chen CY: High levels of EGFR prevent sulforaphane-induced reactive oxygen species-mediated apoptosis in non-small-cell lung cancer cells. Phytomedicine 64: 152926, 2019.

153. Bollu LR, Katreddy RR, Blessing AM, Pham N, Zheng B, Wu X and Weihua Z: Intracellular activation of EGFR by fatty acid synthase dependent palmitoylation. Oncotarget 6: 34992-35003, 2015.

154. Ali A, Levantini E, Teo JT, Goggi J, Clohessy JG, Wu CS, Chen L, Yang H, Krishnan I, Kocher O, et al: Fatty acid synthase mediates EGFR palmitoylation in EGFR mutated non-small cell lung cancer. EMBO Mol Med 10: e8313, 2018. 
155. Thun MJ, Henley SJ and Patrono C: Nonsteroidal anti-inflammatory drugs as anticancer agents: Mechanistic, pharmacologic, and clinical issues. J Natl Cancer Inst 94: 252-266, 2002.

156. Thun MJ, Jacobs EJ and Patrono C: The role of aspirin in cancer prevention. Nat Rev Clin Oncol 9: 259-267, 2012.

157. Ali R, Toh HC, Chia WK; ASCOLT Trial Investigators: The utility of Aspirin in Dukes C and High Risk Dukes B Colorectal cancer - The ASCOLT study: Study Protocol for a randomized controlled trial. Trials 12: 261, 2011.

158. Jafari N, Drury J, Morris AJ, Onono FO, Stevens PD, Gao T Liu J, Wang C, Lee EY, Weiss HL, et al: De novo fatty acid synthesis-driven sphingolipid metabolism promotes metastatic potential of colorectal cancer. Mol Cancer Res: Aug 28, 2018 (Epub ahead of print). https://doi.org/10.1158/1541-7786. MCR-18-0199.
159. Heuer TS, Ventura R, Mordec K, Lai J, Fridlib M, Buckley D and Kemble G: FASN Inhibition and Taxane Treatment Combine to Enhance Anti-tumor Efficacy in Diverse Xenograft Tumor Models through Disruption of Tubulin Palmitoylation and Microtubule Organization and FASN Inhibition-Mediated Effects on Oncogenic Signaling and Gene Expression. EBioMedicine 16: 51-62, 2017.

160. Tsai TH, Chen E, Li L, Saha P, Lee HJ, Huang LS, Shelness GS, Chan L and Chang BH: The constitutive lipid droplet protein PLIN2 regulates autophagy in liver. Autophagy 13: 1130-1144, 2017. International (CC BY-NC-ND 4.0) License. 